\title{
Disguising agents for transmitting Novel Severe Acute Respiratory Syndrome Coronavirus-2 (SARS-CoV-2): Mobile phone \& Paper
}

\section{currency}

\author{
Otun Saha $^{1}$, Nadira Naznin Rakhi ${ }^{1}$, Ovinu Kibria Islam ${ }^{1}$, and Md. Mizanur Rahaman ${ }^{1}$ \\ ${ }^{1}$ Affiliation not available
}

May 21, 2020

\section{Disguising agents for transmitting Novel Severe Acute Respiratory Syndrome Coronavirus-2 (SARS-CoV-2): Mobile phone \& Paper currency}

\author{
Otun Saha ${ }^{1}$, Nadira Naznin Rakhi ${ }^{2}$, Ovinu Kibria Islam ${ }^{1,3}$, Md. Mizanur Rahaman ${ }^{\text {* }}$ \\ ${ }^{1}$ Department of Microbiology, University of Dhaka, Dhaka 1000, Bangladesh \\ ${ }^{2}$ Department of Biotechnology and Genetic Engineering, Bangabandhu Sheikh Mujibur Rahman Science and \\ Technology University, Gopalganj, Bangladesh.
}

${ }^{3}$ Department of Microbiology, Jashore University of Science and Technology, Jashore 7408, Bangladesh

*Correspondence: Dr. Md. Mizanur Rahaman, Department of Microbiology, University Street, Dhaka-1000, Bangladesh.razu002@du.ac.bd; +8801796585290

Dear Editor,

The world is facing the Corona Virus Disease-2019 (COVID-19) pandemic [1], which is also a highly communicable disease disseminating from droplet, contact, fecal-oral transmission along with transmission through fomites [2]. While the frequent handwashing is recommended for preventing the transmission of SARS-CoV-2 [1], the causative agent of COVID-19, we might have unseen the importance of avoiding two prominent vectors of disease transmission: mobile phones and paper currency. According to a recent survey, the total number of mobile phone users worldwide is increasing continuously surpassing 4.8 billion (https://www.statista.com/statistics/274774/forecast-of-mobile-phone-users-worldwide/). These daily essential accessories can be a potential reservoir for SARS-CoV-2, as this virus is secreted in saliva, respiratory secretion and even sweat as well [2]. Considering the threat, Apple, one of the top mobile manufacturer companies holding $22.4 \%$ market share in 2019 has already recommended disinfecting apple products with $70 \%$ alcohol wipe or clorox, which was previously not permitted to protect the phone's oleophobic (oil-repellant) and hydrophobic (water-repellent) coatings. While there has not been any scientific study yet on this regard, a myriad of microorganisms including nosocomial pathogens has already been reported from the surface of mobile phones [3]. In a recent study, SARS-CoV-2 has been claimed to be viable and infectious in aerosols for hours (https://www.thehindu.com/sci-tech/health/how-long-does-sars-cov-2-staypotent/article31259761.ece). Other studies indicated that, SARS-CoV-2 can remain infectious on inanimate surfaces for up to nine days at room temperature [2]. Considering these factors, the possibility of spreading COVID-19 from mobile phones of infected individuals was affirmed by various researcher and also stated that the virus can remain viable on smartphone screen up to 96 hours, if it's made of glass [4]. Furthermore, paper currency is even more used daily object which changes hands numerous times a day and can act as potential vector of viral disease transmission. Previously, human influenza viruses were reported to be viable 
and infectious up to 17 days on paper notes [5]. Some In vitro culture studies also showed that paper currency can harbor high levels of microbes, some of which are clinically significant in causing pneumonia and enteric diseases [6]. Similarly, nasal inoculation particularly with rhinovirus via contaminated fingers was found viable for long time (2-5days) [4]. Although, this sort of studies have not been conducted for SARS-CoV-2,considering the possible potential of paper currency as a vector, World Health Organization (WHO) has advised taking measures to maintain proper hygiene post handling of notes. After Covid-19 outbreak, China undertook the disinfection of cash through ultraviolet light, high temperatures, quarantining it for 14 days etc. But in many countries, people are not aware of the possible danger of handling the cash without maintaining proper hygiene. While we have been focusing on sanitizing and washing our hands countless times a day, most of us have forgotten the smartphone and banknotes, which in many ways is a possible reservoir of life threatening viruses. Covert transmission of COVID-19 through asymptomatic patients [1.2] also indicate the threat of disseminating the SARS-CoV-2 through these fomites. Although it has been claimed that, disease transmission from paper notes and mobile phones may contributes minutely, approximately $1 \%[2,4]$, the transmissibility may vary due to the population density, hygiene practice and many other factors. But as the paper notes and mobile phone can be the easiest carrier of communicable diseases, raising awareness about the transmission from those frequently used inanimate objects should be encouraged. In conclusion, it is recommended that along with hand washing and other personal hygiene strategy, appropriate safety precaution is needed to be taken to limit the risk of spreading Covid-19 from mobile phones and banknotes.

\section{Author's contributions}

O.S., N.N.R and O.K.I carried out the studies (Data collection and data analysis). O.S., N.N.R drafted the manuscript. M.M.R. developed the hypothesis, supervised the whole work and M.M.R and O.K.I critically reviewed the drafted manuscript. All authors read and approved the final manuscript.

\section{Acknowledgments}

The authors would like to acknowledge Bangladesh Bureau of Education Information and Statistics (BANBEIS) for research grant No. LS2019935 to M.M.R. and Bangabandhu Science \& Technology Fellowship Trust for supporting O.S. with PhD fellowship.

\section{Conflict of interest}

The authors declare that the research was conducted in the absence of any commercial or financial relationships that could be construed as a potential conflict of interest.

\section{Funding source}

No Funding

\section{References}

Sahin, A. R., Erdogan, A., Agaoglu, P. M., Dineri, Y., Cakirci, A. Y., Senel, M. E., \& Tasdogan, A. M. 2019 Novel Coronavirus (COVID-19) Outbreak: A Review of the Current Literature. EJMO 2020; 4(1):1-7.

Yee, J., Unger, L., Zadravecz, F., Cariello, P., Seibert, A., Johnson, M. A., \& Fuller, M. J..Novel coronavirus 2019 (COVID-19): Emergence and implications for emergency care. J of the American College of Emergency Physicians Open 2020.

Ulger, F., Esen, S., Dilek, A., Yanik, K., Gunaydin, M., \& Leblebicioglu, H. Are we aware how contaminated our mobile phones with nosocomial pathogens?. Annals of clinic. Microbial. and antimicrobials 2009; 8(1):7.

Kampf, G., Todt, D., Pfaender, S., \& Steinmann, E. Persistence of coronaviruses on inanimate surfaces and its inactivation with biocidal agents. J. of Hospital Infect 2020.

Thomas, Y., Vogel, G., Wunderli, W., Suter, P., Witschi, M., Koch, D., \& Kaiser, L. Survival of influenza virus on banknotes. Appl. Environ. Microbiol 2008; 74(10):3002-3007. 
Gedik, H., Voss, T. A., \& Voss, A. Money and transmission of bacteria. Antimicrobial res. and infect. Cont 2015; 2(1): 22 .

Thomas, Y., Vogel, G., Wunderli, W., Suter, P., Witschi, M., Koch, D., \& Kaiser, L. Survival of influenza virus on banknotes. Appl. Environ. Microbiol 2008; 74(10):3002-3007. 